\title{
Effects of electric-arc furnace dust application on soil properties, sorghum growth, and heavy-metal accumulation
}

\begin{abstract}
This study investigated the possibility of using electric-arc furnace dust (EAFD) as an acidic soil amendment. The experiments were conducted using incubation and pot experiments. In the incubation experiment, various rates of EAFD were added to an acidic soil and properties such as $\mathrm{pH}$; electrical conductivity of the saturation extract (ECse); and available phosphorus $(\mathrm{P})$, potassium $(\mathrm{K})$, iron $(\mathrm{Fe})$, zinc $(\mathrm{Zn})$, copper $(\mathrm{Cu})$, manganese $(\mathrm{Mn})$, lead $(\mathrm{Pb})$, and cadmium $(\mathrm{Cd})$ were determined. In the pot experiment rates of EAFD incorporated with soil were $0.25 \%, 0.5 \%, 1 \%$, and $2 \%$. The results showed that with increasing the rate of EAFD application, soil $\mathrm{pH}, \mathrm{EC}$, and available $\mathrm{P}$ and $\mathrm{K}$ were enhanced. However, addition of EAFD more than $2 \%$ caused high salinity and alkalinity; hence, it is not recommended for reclamation of this acidic soil. A pot experiment was carried out to determine its effects on sorghum (Sorghum bicolor L.) dry matter and heavy-metal accumulation. Plant dry matter was enhanced with increase the EAFD rates. The concentrations of $\mathrm{Fe}, \mathrm{Zn}, \mathrm{Cu}, \mathrm{Cd}$, and $\mathrm{Pb}$ were enhanced with the increasing rate of applied EAFD in root and shoot. However, content of these elements in plant shoot were in the normal range.
\end{abstract}

Keyword: Acidic soil; EAFD; Heavy metals; Soil salinity; Sorghum 